\title{
The Molecular Basis of Vernalization in Different Plant Groups
}

\author{
T.S. REAM, ${ }^{1,2,5}$ D.P. Woods, ${ }^{1,3,4,5}$ AND R.M. Amasino ${ }^{1,3}$ \\ ${ }^{1}$ Department of Biochemistry, University of Wisconsin, Madison, Wisconsin 53706 \\ ${ }^{3}$ Great Lakes Bioenergy Research Center, United States Department of Energy, Madison, Wisconsin 53706 \\ ${ }^{4}$ Laboratory of Genetics, University of Wisconsin, Madison, Wisconsin 53706 \\ Correspondence: amasino@biochem.wisc.edu
}

\begin{abstract}
Timing of flowering is key to the reproductive success of many plants. In temperate climates, flowering is often coordinated with seasonal environmental cues such as temperature and photoperiod. Vernalization, the process by which a prolonged exposure to the cold of winter results in competence to flower during the following spring, is an example of the influence of temperature on the timing of flowering. In different groups of plants, there are distinct genes involved in vernalization, indicating that vernalization systems evolved independently in different plant groups. The convergent evolution of vernalization systems is not surprising given that angiosperm families had begun to diverge in warmer paleoclimates in which a vernalization response was not advantageous. Here, we review what is known of the vernalization response in three different plant groups: crucifers (Arabidopsis), Amaranthaceae (sugar beet), and Pooideae (wheat, barley, and Brachypodium distachyon). We also discuss the advantages of using Brachypodium as a model system to study flowering and vernalization in the Pooids. Finally, we discuss the evolution and function of the Ghd7/VRN2 gene family in grasses.
\end{abstract}

Flowering when conditions are most favorable for pollination, seed development, and seed dispersal is an important adaptive trait. Many plants that are adapted to temperate climates synchronize their flowering to coincide with seasons by monitoring cues such as temperature and photoperiod. Vernalization is one adaptation to a temperature cue; it is the process by which plants become competent to flower only after prolonged exposure to the cold of winter, thereby ensuring that flowering occurs under favorable conditions in spring (Amasino 2004; Kim et al. 2009; Amasino and Michaels 2010).

In addition to crucifers, there are only two other families of plants, Poaceae and Amaranthaceae, for which something is known about the vernalization response at the molecular level. The genes conferring the vernalization response in the cereals wheat and barley (Poaceae) and sugar beet (Amaranthaceae) are different from the FRI/FLC module in crucifers. That different genes are involved in establishing the vernalization requirement in Arabidopsis, beets, and cereals is not surprising because flowering plants were diverging in an era when continents were in different locations and the planet was warmer, and thus vernalization systems were likely to have adaptive value only after different flowering plant lineages became established (Amasino 2010).

\section{The Vernalization Requirement in Arabidopsis thaliana}

The study of the vernalization response in Arabidopsis, which dates back to the 1940s (see, e.g., Laibach 1943), is a classic example of the value of studying natural variation. Klaus Napp-Zinn extended these studies and established that in crosses of certain vernalization-requiring accessions to rapid-flowering accessions, the vernalization requirement was often attributable to a dominant gene that he called FRIGIDA (FRI) (Napp-Zinn 1987). Subsequent studies showed that the same dominant gene is necessary for the vernalization requirement in a wide range of accessions (Burn et al. 1993; Lee et al. 1993; Clarke and Dean 1994; Koornneef et al. 1994). Furthermore, two studies showed that a second gene, FLOWERING LOCUS C (FLC), is necessary for FRI to create a vernalization requirement (Koornneef et al. 1994; Lee et al. 1994).

The subsequent cloning and characterization of FRI and FLC provided a molecular framework for the vernalization requirement in Arabidopsis. FLC encodes a MADS-box-containing DNA-binding protein that functions as a repressor of flowering, and $F R I$ up-regulates $F L C$ to a level that effectively prevents flowering in the

\footnotetext{
${ }^{2}$ Thomas S. Ream is a Gordon and Betty Moore Fellow of the Life Sciences Research Foundation.

${ }^{5}$ These authors contributed equally to this work.
} 
fall season (Michaels and Amasino 1999; Sheldon et al. 1999). Indeed, FLC can repress flowering without FRI when $F L C$ expression is driven from a strong promoter. $F L C$ is part of a gene family (often referred to as the FLC clade) in which there are five other genes: FLOWERING LOCUS M (FLM)/MADS AFFECTING FLOWERING 1 (MAF1), MADS AFFECTING FLOWERING 2 (MAF2), MADS AFFECTING FLOWERING 3 (MAF3), MADS AFFECTING FLOWERING 4 (MAF4), and MADS AFFECTING FLOWERING 5 (MAF5). Many of these FLC relatives have also been shown to act as floral repressors (Ratcliffe et al. 2001, 2003; Scortecci et al. 2001), but when FRI is present FLC typically accounts for most of the flower-repressing activity that creates a vernalization requirement.

As noted above, much of the natural variation for flowering in Arabidopsis results from allelic variation at FRI. Loss of FRI results in rapid flowering and loss of the vernalization requirement. To date, a large number of independent loss-of-function fri alleles have been identified in a range of Arabidopsis accessions (see, e.g., Scarcelli and Kover 2009). Thus, the "original" Arabidopsis contained an active $F R I$ allele and was vernalization responsive, but the recurrent loss of FRI is likely to have provided an advantage in certain environments.

Why is FRI the locus at which much of the natural variation for flowering resides? FRI is a member of a gene family that is unique to plants (see, e.g., Johanson et al. 2000; Michaels et al. 2004), but it may be the only nonredundant member of the family devoted exclusively to flowering-time control; that is, loss of FRI is a single change that eliminates the vernalization requirement without pleiotropic effects. Two other members of the FRI family, FRIGIDA LIKE 1 (FRL1) and FRIGIDA LIKE 2 (FRL2), act redundantly with each other, but nonredundantly with FRI, to establish the vernalization requirement (Michaels et al. 2004; Schlappi 2006).

As expected, FRI and FRLs do not act alone to up-regulate FLC. Genetic screens for loss of the vernalization requirement have identified other necessary components. Some of these appear to be specific to FRI-mediated FLC activation because mutations in these components eliminate the vernalization requirement without pleiotropic effects. These FRI-specific modifiers include SUPPRESSOR OF FRI4, FRI ESSENTIAL1, and FLC EXPRESSOR
(Schmitz et al. 2005; Kim and Michaels 2006; Kim et al. 2006; Andersson et al. 2008). A recent biochemical study indicates that FRI, FRL, and all of these other components are part of a complex (the FRIGIDA complex) that interacts with the FLC promoter (Choi et al. 2011).

In outline, the process by which FLC creates a vernalization requirement is straightforward (Fig. 1). FLC blocks flowering by binding to and suppressing key genes that promote flowering in the photoperiod pathway. Major targets of FLC include the flowering promoters $F T, F D$, and SUPPRESSOR OF OVEREXPRESSION OF CONSTANS 1 (SOC1) (Hepworth et al. 2002; Helliwell et al. 2006; Searle et al. 2006). As shown by Searle et al. (2006), for $F L C$ to be effective it must be expressed both in the vascular tissue of young leaves (to suppress FT) and in meristems (to suppress FD and SOC1). In Arabidopsis and rice, $F T$ acts as a flowering signal called florigen that translocates from leaves to the meristem, in which it physically interacts with the basic leucine zipper (bZIP) transcription factor $F D$ to initiate flowering by activating downstream genes including SOC1 (Corbesier et al. 2007; Jaeger and Wigge 2007; Mathieu et al. 2007; Tamaki et al. 2007; Amasino 2010).

The mechanism by which FLC represses targets is not fully understood. MADS-domain proteins typically function as multimers with other MADS-domain proteins (see, e.g., Honma and Goto 2001; de Folter et al. 2005) and bind to DNA in a site-specific manner. SHORT VEGETATIVE PHASE (SVP) is another MADS-domain protein that interacts with FLC and binds to FLC target genes. Loss of SVP partially suppresses the ability of FLC to inhibit flowering (Lee et al. 2007; Fujiwara et al. 2008; Li et al. 2008). Thus, SVP appears to be part of an FLC repressor complex, but because loss of SVP does not affect flowering as strongly as does loss of FLC, there may be some redundancy in SVP function (Amasino 2010). SVP also interacts with LIKE HETEROCHROMATIN 1 (LHP1) (Liu et al. 2009), indicating that FLC repression may involve chromatin modification.

The process of vernalization in Arabidopsis accomplishes FLC silencing (Fig. 1). Vernalization involves the sensing of cold, the induction of certain components involved in modifications to FLC chromatin, and the stable maintenance of FLC silencing. Little is known about
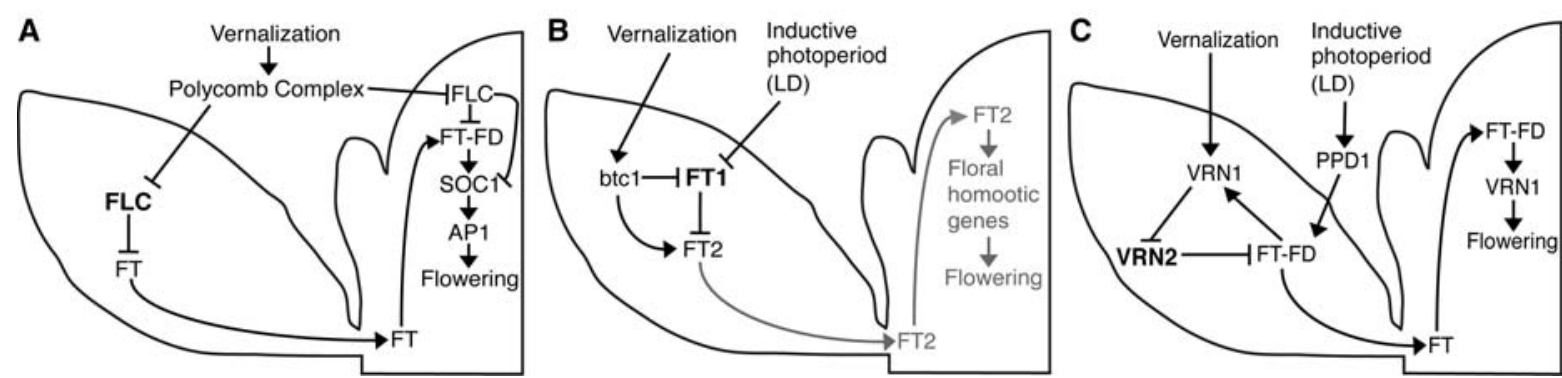

Figure 1. Overview of the pathways by which vernalization leads to flowering in Arabidopsis, beet, and wheat. (A) Arabidopsis flowering pathway, $(B)$ beet flowering pathway, $(C)$ wheat/barley flowering pathway. Floral repressors are highlighted in bold. Gray arrows and text show parts of a pathway that are presumed to be conserved in this species but have not been experimentally shown. 
the mechanism of cold sensing for the vernalization response in Arabidopsis or in any plant species. In contrast, there has been much progress toward elucidating the molecular mechanism of cold sensing that is involved in the process of cold acclimation (see, e.g., Doherty et al. 2009). The progress in cold acclimation has been achieved primarily from biochemical and molecular genetic approaches (working "back" from cold-induced genes), and a similar approach might result in progress in cold sensing during vernalization. It is important to note that cold acclimation is a relatively rapid response to cold (minutes to hours), whereas vernalization requires days to weeks of cold exposure. It is possible that cold sensing as it relates to vernalization and to cold acclimation has some common features, with the vernalization system simply requiring a longer period of whatever biochemical changes that cold acclimation causes, but studies of plants in which cold acclimation is altered have not revealed any changes to vernalization.

During vernalization, chromatin changes at FLC include a reduction of histone acetylation and an increase in the repressive methylation of histone $\mathrm{H} 3$ at lysines 9 and 27 (Bastow et al. 2004; Sung and Amasino 2004). These changes require cold induction of VERNALIZATION INSENSTIVE 3 (VIN3) (Sung and Amasino 2004), a gene encoding a PHD domain that is part of the plant POLYCOMB REPRESSION COMPLEX 2 (PRC2) (Wood et al. 2006; De Lucia et al. 2008). PRC2 catalyzes methylation of histone $\mathrm{H} 3$ at lysine 27 , and the PRC2 complex that represses FLC requires, in addition to VIN3, two VIN3 relatives (VIN3-LIKE 1 [VIL1]/ VERNALIZATION5 [VRN5] and VIN3-LIKE 2 [VIL2]/ VEL1 [VERNALIZATION-LIKE 1]) (Sung et al. 2006b; Greb et al. 2007; De Lucia et al. 2008). These changes begin during the cold in a region that contains parts of the first exon and intron of FLC and spreads throughout the FLC locus during and after cold exposure (Finnegan and Dennis 2007; De Lucia et al. 2008; Angel et al. 2011). Also induced during cold exposure is a noncoding sensestrand RNA derived from the FLC locus known as COLDAIR (Heo and Sung 2011), and a group of noncoding antisense transcripts, termed COOLAIR, that initiate in the area of the $3^{\prime}$ untranslated region of the FLC mRNA (Swiezewski et al. 2009; Liu et al. 2010). The role of COOLAIR is not known because plants lacking these transcripts undergo vernalization (Helliwell et al. 2011), and COLDAIR is thought to enhance the recruitment of PRC2 to the FLC locus (Heo and Sung 2011).

The "locking in" of a stable state of FLC repression after cold exposure requires VERNALIZATION (VRN1) (Levy et al. 2002), LIKE HETEROCHROMATIN PROTEIN1 (LHP1) (Mylne et al. 2006; Sung et al. 2006a), and PROTEIN ARGININE METHYLTRANSFERASE 5 (AtPRMT5) (Schmitz et al. 2008), and the stable silencing is also associated with methylation of histone $\mathrm{H} 3$ at lysine 9 (Sung et al. 2006a). In animals, stable maintenance of PRC2 repression involves PRC1, but plants do not have PRC1 components so LHP1, VRN1, AtPRMT5, and lysine 9 methylation may have a PRC1-like role (Kim et al. 2009).

\section{Vernalization in Amaranthaceae}

In sugar beets, three genes have a role in the vernalization response, namely, $B v B T C 1, B v F T 1$, and $B v F T 2$ (Fig. 1). $B v F T 1$ and $B v F T 2$ are part of a phosphatidylethanolamine-binding protein (PEBP) gene family in plants. PEBP-like genes are classified into three subfamilies: FT (FLOWERING LOCUS T), TFL (TERMINAL FLOWER), and MFT (MOTHER OF FT) (Kobayashi et al. 1999; Chardon and Damerval 2005). Genes in the FT subfamily can act as floral activators (Kobayashi et al. 1999; Lifschitz et al. 2006; Yan et al. 2006) and genes in the TFL subfamily can act as floral repressors (Pnueli et al. 1998; Kobayashi et al. 1999; Jensen et al. 2001; Nakagawa et al. 2002; Danilevskaya et al. 2010). BvFT1 and BvFT2 are most closely related to FT (Pin et al. 2010). BvFT2 is the functional $F T$ ortholog in beets because overexpression of $B v F T 2$ promotes rapid flowering in the absence of vernalization, and $B v F T 2$-RNAi lines do not flower, indicating that FT2 is required for flowering (Pin et al. 2010). BvFT1 is a flowering repressor despite being in the $F T$ subfamily. Overexpression of $B v F T 1$ in annual sugar beets results in repression of $B v F T 2$ expression and a severe delay in flowering (Pin et al. 2010). Furthermore, like FLC, BvFT1 expression decreases during cold exposure in biennial beets; unlike FLC, however, maintenance of BvFT1 repression after vernalization requires long days (Fig. 1) (Pin et al. 2010).

Natural variation in the vernalization response in sugar beets is controlled by alleles of $B v B T C 1$ (formerly the $B$ locus). Dominant alleles of $B v B T C 1$ (activators of flowering) result in an annual habit, whereas recessive alleles (Bvbtcl) create a vernalization requirement and a biennial growth habit. This is in contrast to Arabidopsis, in which dominant alleles of FRI or FLC (repressors of flowering) create a biennial growth habit, and loss of FRI or FLC results in an annual growth habit. $B v B T C 1$ encodes a pseudoresponse regulator with homology with the Arabidopsis PRR3 and PRR7 genes and PPD-H1 in barley (Pin et al. 2012). Dominant BvBTCl alleles in annual sugar beets are associated with low levels of $B v F T 1$ and high levels of $B v F T 2$, which correlates with rapid flowering in the absence of vernalization, whereas partial loss of function Bvbtcl alleles are associated with high $B v F T 1$, low $B v F T 2$, and are late flowering without vernalization (Pin et al. 2012). Knockdown of $B v B T C 1$ or $B v b t c 1$ by RNAi results in higher levels of $B v F T 1$, lower levels of $B v F T 2$, and lack of flowering (Pin et al. 2012).

Cold treatment of biennial beets induces $B v b t c 1$ and $B v F T 2$ expression and represses $B v F T 1$, resulting in rapid flowering in long days following winter (Pin et al. 2012). Thus, one possible model for vernalization in biennial beets is the presence of a Bvbtcl allele that can only repress $B v F T 1$ after it is induced by cold. Cold treatment results in enough functional $B v b t c 1$ to repress $B v F T 1$, allowing for high levels of BvFT2.

The molecular basis of the difference between the $B v B T C 1$ and $B v b t c 1$ alleles is unknown. The biennial habit could be conferred by a change in expression levels of Bvbtcl or by production of an impaired Bvbtc1 protein. 
Interestingly, a $28-\mathrm{kb}$ insertion present in the promoter region of biennial beets (and not annuals) disrupts a series of sequence motifs found in light-regulated promoters (Pin et al. 2012). In biennial sugar beets, Bvbtcl expression is slightly lower at the end of the light period compared to annual sugar beets, and this is associated with higher $B v F T 1$ levels and lower BvFT2 levels (Pin et al. 2012). There are at least two additional bolting loci (B2 and B3) that create a vernalization requirement in annual beets in the presence of the dominant $B v B T C 1$ allele (Buttner et al. 2010). The cloning and characterization of these loci will hopefully inform our understanding of the network controlling flowering in beets.

\section{Vernalization in Cereals}

Thus far, only a handful of genes have been found to participate in a regulatory loop that controls the timing of flowering in cereals in response to temperature and photoperiod (Fig. 1), namely, VERNALIZATION1 (VRN1), VERNALIZATION2 (VRN2) PHOTOPERIOD-H1 (PPD$H 1$ ), and $F T$ (formerly VRN3) (for review, see Dennis and Peacock 2009; Distelfeld et al. 2009; Greenup et al. 2009). Epistatic relationships among VRN1, VRN2, PPD-H1, and $F T$ have been revealed by the study of existing allelic variants in these genes from wild and domesticated varieties of wheat and barley (Trevaskis et al. 2003; Yan et al. 2003, 2004b, 2006; Dubcovsky et al. 2005; Karsai et al. 2005; Turner et al. 2005; Hemming et al. 2008; Shimada et al. 2009). Particular varieties of spring barley and spring wheat that do not require vernalization either carry deletions of the VRN2 locus or point mutations in the conserved CCT domain of VRN2 (Yan et al. 2004b; Dubcovsky et al. 2005; Karsai et al. 2005; von Zitzewitz et al. 2005). Therefore, an active VRN2 is necessary for a vernalization requirement. Other spring varieties have dominant alleles of VRN1 or FT that are constitutively activated and epistatic to functional VRN2 alleles (Yan et al. 2003, 2004a, 2006; Fu et al. 2005; Loukoianov et al. 2005; von Zitzewitz et al. 2005). Allelic variation at the $P P D-H 1$ locus results in two types of spring varieties that are either sensitive to photoperiod and early flowering $(P P D-H 1)$ or insensitive to photoperiod and later flowering ( $p p d-h 1)$ (Turner et al. 2005).

In the fall, high levels of VRN2 in leaves repress FT in winter varieties and prevent flowering (Yan et al. 2004b). Furthermore, ubiquitous expression of VRN2 delays heading in long days (Hemming et al. 2008). VRN2 is in the COlike gene family and contains a zinc finger and a CCT domain (Yan et al. 2004b; Higgins et al. 2010). Although $V R N 2$ acts similarly to $F L C$ as a floral repressor, it is unrelated to $F L C$, and thus far no FLC orthologs are known in grasses.

In wheat and barley, VRN2 levels decrease during cold exposure and VRN1 levels increase (Yan et al. 2003, 2004b; Dubcovsky et al. 2006; Trevaskis et al. 2006; Preston and Kellogg 2008; Sasani et al. 2009). VRN1 is related to the APETALA1 (API)/CAULIFLOWER $(C A L) /$ FRUITFUL $(F U L)$ family of MADS box transcription factors that control floral meristem identity in
Arabidopsis (Yan et al. 2003; Preston and Kellogg 2008). In Arabidopsis, AP1, CAL, and FUL are expressed primarily in meristems (Liljegren et al. 1999), whereas in grasses VRN1 is expressed in both meristems and leaves (Trevaskis et al. 2003; Yan et al. 2003; Preston and Kellogg 2008; Sasani et al. 2009; Alonso-Peral et al. 2011). Activation of VRN1 during cold is accompanied by changes in chromatin in a presumed regulatory region of its first intron (Oliver et al. 2009). Opposite to that of the coldrepressed $F L C$, but expected for that of a cold-induced gene, $V R N 1$ chromatin modifications shift from repressive (H3K27 methylation) to active (H3K4 methylation) during vernalization (Oliver et al. 2009).

In support of a model in which VRN1 is a repressor of $V R N 2$, high levels of $V R N 1$ early in development in lines harboring dominant $V R N 1$ alleles are associated with low levels of VRN2 (Loukoianov et al. 2005; Hemming et al. 2008; Distelfeld et al. 2009). Furthermore, vrn1 mutants have elevated levels of VRN2 after vernalization, suggesting that VRN1 has a role in maintaining repression of VRN2 after vernalization (Chen and Dubcovsky 2012). However, VRN2 levels still decrease during vernalization in vrn 1 mutants, suggesting additional levels of control of the repression of VRN2 during cold in wheat (Chen and Dubcovsky 2012). Interestingly, vrn 1 mutants still flower and produce seeds, although the mutants are delayed compared to wild-type plants. That vrn 1 mutants are still able to flower suggests possible redundancy among VRN1-like genes found in grasses (Preston and Kellogg 2008; Chen and Dubcovsky 2012).

After vernalization in the spring, low VRN2 levels allow for activation of FT by PPD-H1 and other components of the photoperiod pathway in leaves and ultimately a switch from vegetative to floral meristem identity and flowering (Sasani et al. 2009). PPD-H1 encodes a pseudoresponse regulator with a CCT domain that is required for high levels of FT in spring-sown barley (Turner et al. 2005). High levels of $F T$ are associated with high levels of VRN1 expression in leaves, indicating the possibility of a positive feedback loop between VRN1 and FT to "lock in" flowering (Yan et al. 2006; Shimada et al. 2009; Distelfeld and Dubcovsky 2010). One part of this feedback loop is supported by the observation that, in vitro, FT physically interacts with the FD ortholog FDL2, and this complex binds to the VRN1 promoter (Li and Dubcovsky 2008).

One proposed mechanism for higher FT expression in long days following vernalization is that before vernalization, there is competition between the CCT proteins CONSTANS-LIKE 2 and VRN2 for a common set of NUCLEAR FACTOR-Y (NF-Y)-related subunits (Li et al. 2011). In Arabidopsis, particular NF-Y subunits are required for promotion of flowering in long days by physically interacting with CONSTANS and directly regulating FT expression (Kumimoto et al. 2008, 2010). After vernalization, VRN2 expression is low and thus competition is reduced, causing increased FT expression. In support of this model in grasses, CONSTANS-LIKE 2 and VRN2 compete for a common set of NF-Y subunits as determined by in vitro yeast-two-hybrid and yeast-three-hybrid assays 
(Li et al. 2011). Furthermore, the CCT domains of allelic variants of VRN2 that result in a spring habit show a decreased ability to compete with CONSTANS-LIKE 2 for these NF-Y subunits in vitro (Li et al. 2011).

\section{Brachypodium distachyon as a Model for Flowering Time in Grasses}

Although there has been great progress made in understanding the vernalization pathway in wheat and barley, much remains to be learned, including the extent to which vernalization pathways are conserved in grasses. Brachypodium distachyon is a small, wild relative of temperate grasses within the Pooideae, which includes many important cereal crops such as wheat, barley, oats, and rye. Brachypodium is a useful model grass because of its small, completely sequenced diploid genome (Vogel 2010), simple growth requirements, large collection of accessions, inbreeding nature, and high rate of recombination (Draper et al. 2001; Vogel et al. 2006, 2009; Opanowicz et al. 2008; Filiz et al. 2009; Brkljacic et al. 2011; Huo et al. 2011; Mur et al. 2011). All of these characteristics make Brachypodium an attractive model for studying flowering time in general, and the vernalization response in particular, in a temperate grass.

The availability of high-quality genome sequences of many Brachypodium accessions enables the identification of mutations by whole-genome sequencing of bulked mutant segregants derived from crosses between the mutant line and a polymorphic accession (Schneeberger et al. 2009; Austin et al. 2011; Minevich et al. 2012). One bottleneck has been the cost and analysis of the resulting genome datasets, but user-friendly web-based pipelines to assist with such analyses are becoming more common and will accelerate mutant identification (see, e.g., Austin et al. 2011; Minevich et al. 2012). Indeed, we have successfully used whole-genome sequencing of bulked segregants to identify causal mutations in several Brachypodium flowering-time mutants using CLOUDmap software (Minevich et al. 2012; TS Ream, DP Woods, and RM Amasino, unpubl.). Brachypodium has a small genome size of only $272 \mathrm{Mb}$, compared to the $17 \mathrm{~Gb}$ of bread wheat (Brenchley et al. 2012) and 5 Gb of barley (International Barley Genome Sequencing et al. 2012). Thus, mapping mutations in Brachypodium using whole-genome technologies is simpler and significantly less expensive than such an effort in wheat or barley.

Several studies have characterized flowering behavior in certain Brachypodium accessions, revealing some of the range of cold duration required to satisfy (or saturate) the vernalization requirement (Draper et al. 2001; Vogel et al. 2009; Schwartz et al. 2010). Our studies show that there is rich natural diversity to explore for flowering time variation, with some lines requiring little or no cold exposure to flower in extended photoperiods, whereas other accessions have obligate cold exposure requirements ranging in duration from $2-16 \mathrm{wk}$ (Fig. 2). However, little is known about vernalization in Brachypodium at the molecular level. To advance Brachypodium as a
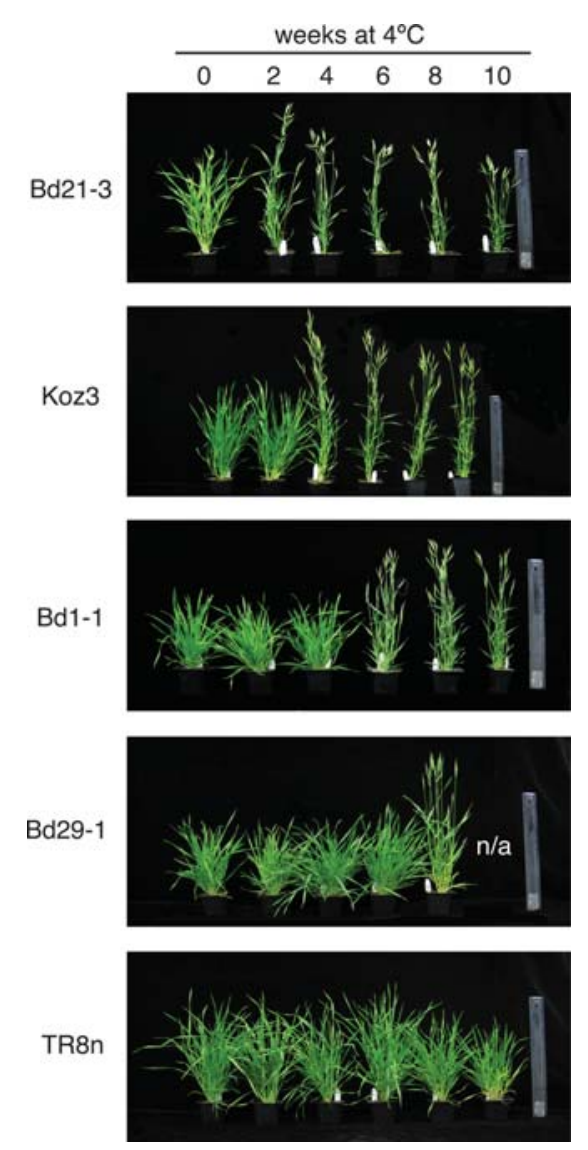

Figure 2. Example of the range of vernalization responses among Brachypodium accessions. Plants were exposed to cold for the indicated number of weeks and then shifted to growth at $16^{\circ} \mathrm{C}$ (plants shown were grown for $60 \mathrm{~d}$ after a shift to $16^{\circ} \mathrm{C}$ ). Note there are accessions with sharp transitions from quite delayed flowering to rapid flowering after $2,4,6$, or $8 \mathrm{wk}$ of cold exposure.

model for studying flowering, we have characterized flowering behavior in a range of accessions in response to varying photoperiods and cold treatments. We found, for example, that accession $\mathrm{Bd} 21-3$ has a varying vernalization requirement depending on the condition in which it is grown. $\mathrm{Bd} 21-3$ flowers rapidly in a $20-\mathrm{h}$ photoperiod with no cold exposure. However, shorter photoperiods progressively delay flowering such that cold treatment (i.e., vernalization) of plants or imbibed seeds is required for rapid flowering (Fig. 3). In contrast, Bd1-1 requires 6-8 wk of vernalization to flower rapidly even in a 20 -h photoperiod (Figs. 2 and 3). Representing extreme cases, accessions such as BdTR8n require up to $16 \mathrm{wk}$ of cold to rapidly flower even in a 20 -h photoperiod (Fig. 2).

\section{Does Brachypodium Have an Ortholog of VRN2 from Wheat and Barley?}

The CCT domain-containing genes Grain number, plant height, and heading date 7 (Ghd7) from rice (Oryza sativa) and VRN2 from cereals, such as wheat and barley, block flowering by repressing the expression of FT 


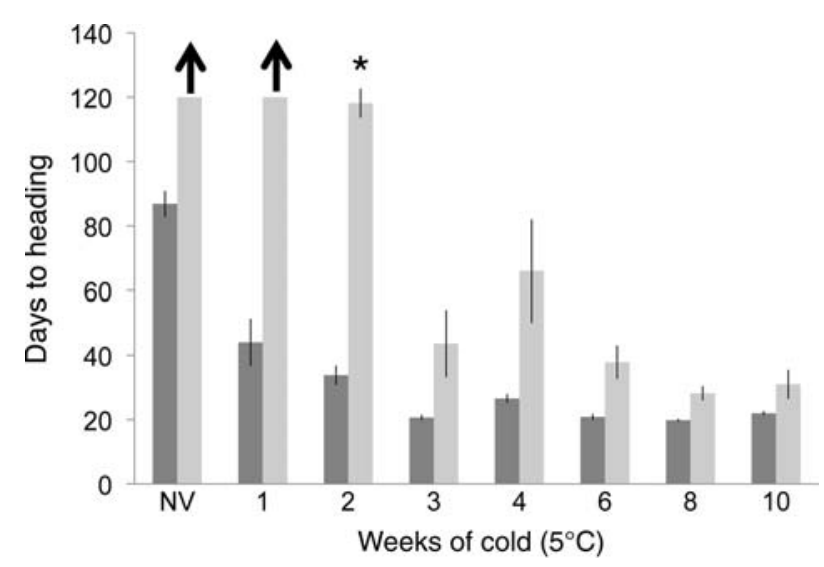

Figure 3. Vernalization time course of two accessions in a 16$\mathrm{h}$ photoperiod, shown as days to flower. Arrows indicate treatments in which plants had not flowered by the end of the experiment (120 d). (Asterisk) Some plants did not flower within this treatment. (Dark bars) Bd 21-3, (light bars) Bd1-1.
(Greenup et al. 2009). Expression of these genes is regulated by photoperiod (Dubcovsky et al. 2006; Trevaskis et al. 2006; Xue et al. 2008); however, cold exposure also represses VRN2 expression (Yan et al. 2004b). Ghd7 and VRN2 are members of a CONSTANS-like (COL) superfamily of genes. All members of this large gene family carry a conserved CCT domain near the carboxyl terminis. The family can be subdivided into five subfamilies based on the presence of different amino-terminal domains (Griffiths et al. 2003; Ballerini and Kramer 2011; Cockram et al. 2012). Ghd7 and VRN2 have been placed in a distinct subfamily because they both lack a B-box domain in the amino terminus (Cockram et al. 2012). Furthermore, phylogenetic evidence based on the conserved CCT domain places group IV members Ghd7, $V R N 2$, and CO9 within a well-supported, monocotspecific CCT motif family (CMF) clade sister to the $C O L$ subgroup I clade that contains $C O$ (Cockram et al. 2012).

Thus far, phylogenetic, and syntenic approaches have not revealed a clear VRN2 or GHD7 ortholog in Brachypodium (Higgins et al. 2010; Cockram et al. 2012; Yang et al. 2012). Higgins et al. (2010), using a neighbor-joining phylogenetic analysis of an amino acid sequence alignment of the CCT domain, placed the closest Brachypodium homolog (Bradi3g10010) in an "intermediate" position between $V R N 2$ and $C O 9$ clades. We argue below that Bradi3g10010 is in fact a VRN2/Ghd7 ortholog. The next closest homolog in Brachypodium, Bradi3g33340, clearly resides in a well-supported $C O 9$ clade containing species spanning grass diversification (Cockram et al. 2012). Additionally, VRN2 and Ghd7 genes are not present within colinear regions in Brachypodium (Cockram et al. 2010; Higgins et al. 2010). The presumed absence of $V R N 2$ led to the hypothesis that $\mathrm{Bd} 21$, a rapid-flowering line that does not require vernalization, may be rapid flowering because it lacks VRN2 and that delayed-flowering Brachypodium accessions that show a vernalization requirement may contain a VRN2 ortholog (Cockram et al. 2010; Higgins et al. 2010). However, recent analyses of genome sequences of vernalization-requiring lines did not identify a sequence more related to VRN2 than Bradi3g10010. This suggests that it is unlikely that $\mathrm{Bd} 21$ is rapid flowering owing to lack of VRN2 (S Gordon, DP Woods, RM Amasino, and J Vogel, unpubl.).

Recently, Yang et al. (2012) traced the evolutionary history of GHD7 from sorghum, maize, rice, and Brachypodium. A total of 28 homologous genes were identified from BLASTP searches and were placed into two major clades based on neighbor-joining phylogenetic methods. Clade I consists of two subclades that contain a wellsupported $C O 9$ clade containing genes from all of the grass species used in this study and a Ghd7 clade containing genes from sorghum, maize, rice, and the Brachypodium sequence Bradi3g10010. The difference in position of Bradi3g10010 in the different analyses is because Yang et al. 2012 did not include a VRN2 sequence from barley and wheat in their analysis.

Our phylogenetic analysis of group IV genes, which incorporated additional sequences from newly sequenced grass genomes and used Bayesian methods to infer relationships, estimated a group IV clade comprised of three subclades, VRN2, Ghd7, and CO9, each containing genes only from grass species (Fig. 4), consistent with (Cockram et al. 2012). The CO9 and Ghd7 subclades are both well supported $(>0.95$ posterior probability, PP). The VRN2 clade was not strongly supported (0.76 PP), which we attribute to limited phylogenetic signal. CO9 and Ghd7 contain sequences spanning grass diversification, except that the Ghd7 subclade does not contain genes for the grass subfamily Pooideae. In contrast, the VRN2 subclade contains only genes from Pooideae. Interestingly, in this analysis Bradi3g10010 is in the VRN2 clade. Furthermore, a BLAST analysis of Bradi3g10010 against the newly sequenced wheat and barley genomes (Brenchley et al. 2012; International Barley Genome Sequencing et al. 2012) identifies VRN2 as the top hit, and querying VRN2 against the Brachypodium genome identifies Bradi3g10010 as the top hit, consistent with the genomes being orthologs.

There are two models for the evolution of the group IV clade in grasses. One is that the whole-genome duplication that occurred at the base of the grass family produced the paralogous Ghd7 and CO9 gene families. Subsequently, there was loss of $G h d 7$ within Pooideae and additional duplications of CCT-like genes within Pooideae, giving rise to VRN2. The other is that the whole-genome 


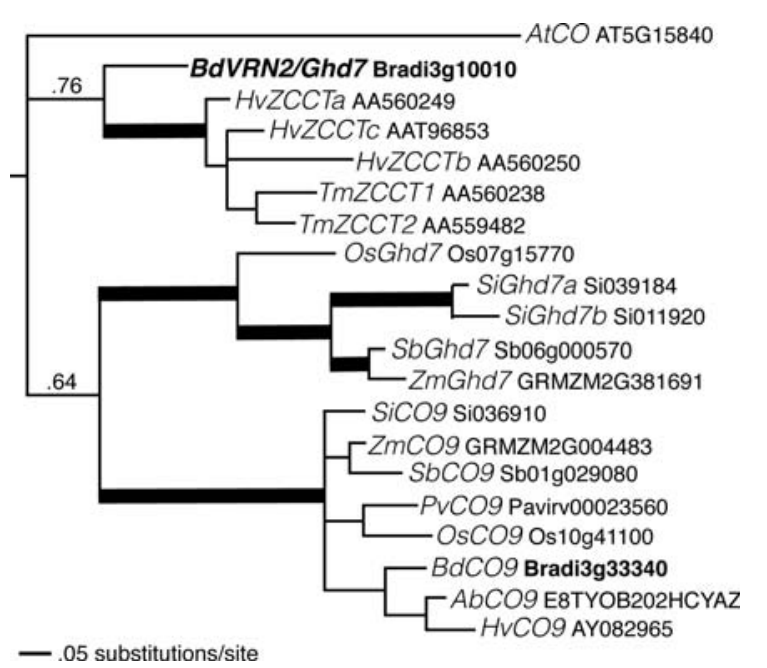

Figure 4. VRN2/GHD7 phylogeny. Bayesian phylogenic analysis estimating the evolutionary relationships among 20 group IV CCT genes based on an alignment using 203 nucleotides of the CCT domain. Bold branches are supported by PP $\geq 0.95$. The VRN2/Ghd7, Bradi3g10010 sequence mentioned in the text is in bold. (At) Arabidopsis thaliana, (Bd) Brachypodium distachyon, (Hv) Hordeum vulgare, (Tm) Triticum monococcum, $(\mathrm{Os})$ Oryza sativa, (Si) Setaria italic, (Sb) Sorghum bicolor, (Zm) Zea mays, (Ab) Avena barbata, (Pv) Panicum virgatum.

duplication at the base of the grass family gave rise to a VRN2 / Ghd7 and a CO9 clade; in this model, VRN2 from Pooids and Ghd7 from other grasses are orthologs despite being in separate clades in this analysis. It is difficult to infer which model best accounts for the evolution of these gene lineages owing to lack of phylogenetic signal, gene movement from syntenic blocks of genes, and the lack of additional sequence from taxa of earlier diverging Pooideae, Ehartoidea, and Bambusoideae (BEP) species. However, the most parsimonious model is that a wholegenome duplication gave rise to the $V R N 2 / G h d 7$ and CO9 clades. Brachypodium's sister relationship with the "crown pooids" containing the crops oats, rye, wheat, and barley will allow us to test if $V R N 2 / G h d 7$ took on a functional role regulating vernalization more broadly throughout that group and perhaps beyond. We refer to Bradi3g10010 as VRN2/Ghd7 reflecting its close evolutionary relationship to these repressors in wheat, barley, and rice.

Given the important role of both Ghd7 and VRN2 in determining the flowering time of rice and wheat/barley, we examined expression of VRN2/Ghd7 in Brachypodium. mRNA levels of $V R N 2 / G h d 7$ are clearly modulated by photoperiod (Fig. 5), consistent with observations of VRN2 in wheat (Dubcovsky et al. 2006; Trevaskis et al. 2006; Distelfeld and Dubcovsky 2010) and Ghd7 in rice (Xue et al. 2008). Plants grown in short days ( $8 \mathrm{~h}$ light $/ 16$ h dark) display lower levels of $V R N 2 / G h d 7$ expression compared to long days (20 h light/ $4 \mathrm{~h}$ dark) (Fig. 5). Additionally, VRN2/Ghd7 expression was examined in Diurnal, which is a database consisting of array expression experiments of samples taken at multiple time points throughout a $48 \mathrm{~h}$ period (Mockler et al. 2007). VRN2/
Ghd7 expression fluctuates diurnally, with peak expression observed during the middle of the light cycle and lowest expression during the dark cycle, consistent with previous studies of orthologs in barley and rice (Trevaskis et al. 2006; Xue et al. 2008).

We have also conducted mutant screens to identify repressors of flowering. To date, our screens have yielded many early-flowering mutants (whose genes presumably encode repressors of flowering), but none of the mutants map in the region of VRN2/Ghd7. Therefore, the role of $V R N 2 / G h d 7$ in Brachypodium flowering remains to be determined. Brachypodium's phylogenetic position sister to the crown pooids offers a great opportunity to investigate the evolution of flowering time in temperate grasses.

\section{Conclusions}

Although vernalization systems in flowering plants are outwardly similar - a block to flowering is alleviated by exposure to the cold of winter - the vernalization systems in three types of plants (crucifers, beets, and cereals) comprise unique components indicating that these systems result from convergent evolution. This is in contrast to the photoperiod pathway of flowering, which is conserved to a large extent in flowering plants. However, the convergent vernalization systems have a common architecture: These systems are "overlayed" on the photoperiod pathway of flowering in a manner that prevents the photoperiod pathway from promoting flowering until repression is relieved by exposure to cold. Much remains to be learned about the vernalization systems of crucifers, beets, and cereals, and novel vernalization systems await discovery as additional branches of the plant kingdom are explored.

\section{MATERIALS AND METHODS}

\section{Plant Growth and Measurements}

Seeds were imbibed overnight in distilled water at $4^{\circ} \mathrm{C}$ before sowing. Individual plants were grown in MetroMix 360 (Sungrow) in plastic pots and fertilized as needed with Peters Excel 15-5-15 Cal-Mag and Peters 10-3020 Blossom Booster (RJ Peters Inc.). Growth chamber temperatures were $23^{\circ} \mathrm{C}$ during the light period and

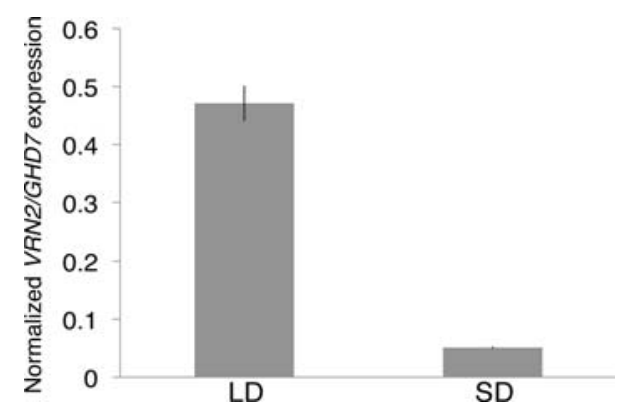

Figure 5. VRN2/GHD7 expression in response to growth in long days (LD) versus short days (SD). 
$18^{\circ} \mathrm{C}$ during the dark period. Plants were grown under T5 fluorescent bulbs $(5000 \mathrm{~K}$, Lithonia) and light intensities averaged $\sim 150 \mu \mathrm{mol} / \mathrm{s}^{2}$ at plant level. The developmental stage was recorded using the Zadoks scale (Zadoks et al. 1974).

\section{Flowering Measurements}

Flowering time of vernalized plants was measured as the number of days from the end of vernalization to the first day on which emergence of the spike was detected $($ Zadoks scale $=50)$.

\section{qPCR}

RNA was extracted from the first leaf of Bd1-1 plants using Trizol (Life Technologies). Each biological replicate consisted of leaf tissue pooled from 4-5 plants. Tissue was harvested in the middle of the photoperiod from plants at approximately equivalent developmental stages (Zadoks scale $=12$ ). RNA purity and integrity was assessed by a combination of A260/A280 and A260/A230 measurements and running samples on a denaturing formaldehyde-agarose gel. cDNA was made using $1 \mu \mathrm{g}$ of total RNA per sample and M-MLV Reverse Transcriptase (Promega) and poly-T primers (IDT). For quantitative polymerase chain reaction (qPCR), $3 \mu \mathrm{L}$ cDNA (diluted fivefold following first-strand synthesis) was amplified using Takara ExTaq II in a $20 \mu \mathrm{L}$ reaction containing $6 \mu \mathrm{L}$ water, $10 \mu \mathrm{L}$ SybrGreen Takara ExTaqII mastermix, and $1 \mu \mathrm{L} 10 \mu \mathrm{M} F+\mathrm{R}$ primers. No reverse transcriptase (RT) reactions were included for each sample. qPCR reactions were amplified on an ABI 7500 Fast system with the following parameters: $95^{\circ} \mathrm{C}$ for $30 \mathrm{sec}$; 40 cycles of $95^{\circ} \mathrm{C}$ for $5 \mathrm{sec}, 60^{\circ} \mathrm{C}$ for $5 \mathrm{sec}$, and $72^{\circ} \mathrm{C}$ for $34 \mathrm{sec}$; followed by a melting curve program. Fluorescence data were collected during the $72^{\circ} \mathrm{C}$ extension steps and during the melting curve program. Gene expression was quantified using the $\Delta \Delta \mathrm{Ct}$ method (Livak and Schmittgen 2001), and primer efficiencies ranged from $95 \%$ to $110 \%$. Expression data for each gene are shown normalized to Brachypodium UBC18 (Hong et al. 2008; Schwartz et al. 2010). An average of three biological replicates is presented for each data point. Standard deviation was calculated on the $2^{-\Delta \mathrm{Ct}}$ values. Primer pairs used to amplify each gene are VRN2F-TCGTAGCGGATCTGC TTCTCGTAG, VRN2R-TCGTAGCGGATCTGCTTCTC GTAG, UBC18F-GTCACCCGCAATGACTGTAAGTT $\mathrm{C}$, and UBC18R-TTGTCTTGCGGACGTTGCTTTG.

\section{Phylogenetic Analysis}

Phylogenetic analyses were performed using VRN2like genes as seed sequences for BLAST searches and trees were generated as described (Woods et al. 2011).

\section{ACKNOWLEDGMENTS}

The authors apologize for not being able to cite all relevant publications owing to length limitations. Daniel
Woods thanks David Baum and Simon Malcomber for helpful discussions regarding VRN2 evolution. This work was funded by the Department of Energy (DOE) Great Lakes Bioenergy Research Center (DOE BER Office of Science DE-FC02-07ER64494) and a National Institutes of Health-sponsored predoctoral training fellowship to the University of Wisconsin Genetics Training Program for D.W.

\section{AUTHOR CONTRIBUTIONS}

T.R., D.W., and R.A. wrote and edited the paper. T.R., D.W., and R.A. designed experiments. T.R. and D.W. performed experiments.

\section{REFERENCES}

Alonso-Peral MM, Oliver SN, Casao MC, Greenup AA, Trevaskis B. 2011. The promoter of the cereal VERNALIZATION1 gene is sufficient for transcriptional induction by prolonged cold. PLOS ONE 6: e29456.

Amasino R. 2004. Vernalization, competence, and the epigenetic memory of winter. Plant Cell 16: 2553-2559.

Amasino R. 2010. Seasonal and developmental timing of flowering. Plant J 61: 1001-1013.

Amasino RM, Michaels SD. 2010. The timing of flowering. Plant Physiol 154: 516-520.

Andersson CR, Helliwell CA, Bagnall DJ, Hughes TP, Finnegan EJ, Peacock WJ, Dennis ES. 2008. The FLX gene of Arabidopsis is required for FRI-dependent activation of FLC expression. Plant Cell Physiol 49: 191-200.

Angel A, Song J, Dean C, Howard M. 2011. A Polycomb-based switch underlying quantitative epigenetic memory. Nature 476: $105-108$.

Austin RS, Vidaurre D, Stamatiou G, Breit R, Provart NJ, Bonetta D, Zhang J, Fung P, Gong Y, Wang PW, et al. 2011. Nextgeneration mapping of Arabidopsis genes. Plant J 67: 715725.

Ballerini ES, Kramer EM. 2011. In the light of evolution: A reevaluation of conservation in the CO-FT regulon and its role in photoperiodic regulation of flowering time. Front Plant Sci 2: 81.

Bastow R, Mylne JS, Lister C, Lippman Z, Martienssen RA, Dean C. 2004. Vernalization requires epigenetic silencing of FLC by histone methylation. Nature 427: 164-167.

Brenchley R, Spannagl M, Pfeifer M, Barker GL, D'Amore R, Allen AM, McKenzie N, Kramer M, Kerhornou A, Bolser D, et al. 2012. Analysis of the bread wheat genome using wholegenome shotgun sequencing. Nature 491: 705-710.

Brkljacic J, Grotewold E, Scholl R, Mockler T, Garvin DF, Vain P, Brutnell T, Sibout R, Bevan M, Budak H, et al. 2011. Brachypodium as a model for the grasses: Today and the future. Plant Physiol 157: 3-13.

Burn JE, Smyth DR, Peacock WJ, Dennis ES. 1993. Genes conferring late flowering in Arabidopsis thaliana. Genetica 90: $147-155$.

Buttner B, Abou-Elwafa SF, Zhang W, Jung C, Muller AE. 2010. A survey of EMS-induced biennial Beta vulgaris mutants reveals a novel bolting locus which is unlinked to the bolting gene B. Theor Appl Genet 121: 1117-1131.

Chardon F, Damerval C. 2005. Phylogenomic analysis of the PEBP gene family in cereals. J Mol Evol 61: 579-590.

Chen A, Dubcovsky J. 2012. Wheat TILLING mutants show that the vernalization gene VRN1 down-regulates the flowering repressor VRN2 in leaves but is not essential for flowering. PLoS Genet 8: e1003134.

Choi K, Kim J, Hwang HJ, Kim S, Park C, Kim SY, Lee I. 2011. The FRIGIDA complex activates transcription of FLC, a 
strong flowering repressor in Arabidopsis, by recruiting chromatin modification factors. Plant Cell 23: 289-303.

Clarke JH, Dean C. 1994. Mapping FRI, a locus controlling flowering time and vernalization response in Arabidopsis thaliana. Mol Gen Genet 242: 81-89.

Cockram J, Howells RM, O'Sullivan DM. 2010. Segmental chromosomal duplications harbouring group IV CONSTANS-like genes in cereals. Genome 53: 231-240.

Cockram J, Thiel T, Steuernagel B, Stein N, Taudien S, Bailey PC, O'Sullivan DM. 2012. Genome dynamics explain the evolution of flowering time CCT domain gene families in the Poaceae. PLoS One 7: e45307.

Corbesier L, Vincent C, Jang S, Fornara F, Fan Q, Searle I, Giakountis A, Farrona S, Gissot L, Turnbull C, et al. 2007. FT protein movement contributes to long-distance signaling in floral induction of Arabidopsis. Science 316: 1030-1033.

Danilevskaya ON, Meng X, Ananiev EV. 2010. Concerted modification of flowering time and inflorescence architecture by ectopic expression of TFL1-like genes in maize. Plant Physiol 153: $238-251$.

de Folter S, Immink RG, Kieffer M, Parenicova L, Henz SR, Weigel D, Busscher M, Kooiker M, Colombo L, Kater MM, et al. 2005. Comprehensive interaction map of the Arabidopsis MADS Box transcription factors. Plant Cell 17: 1424-1433.

De Lucia F, Crevillen P, Jones AM, Greb T, Dean C. 2008. A PHD-polycomb repressive complex 2 triggers the epigenetic silencing of FLC during vernalization. Proc Natl Acad Sci 105: $16831-16836$.

Dennis ES, Peacock WJ. 2009. Vernalization in cereals. J Biol 8: 57.

Distelfeld A, Dubcovsky J. 2010. Characterization of the maintained vegetative phase deletions from diploid wheat and their effect on VRN2 and FT transcript levels. Mol Genet Genomics 283: 223-232.

Distelfeld A, Li C, Dubcovsky J. 2009. Regulation of flowering in temperate cereals. Curr Opin Plant Biol 12: 178-184.

Doherty CJ, Van Buskirk HA, Myers SJ, Thomashow MF. 2009. Roles for Arabidopsis CAMTA transcription factors in coldregulated gene expression and freezing tolerance. Plant Cell 21: $972-984$

Draper J, Mur LA, Jenkins G, Ghosh-Biswas GC, Bablak P, Hasterok R, Routledge AP. 2001. Brachypodium distachyon. A new model system for functional genomics in grasses. Plant Physiol 127: 1539-1555.

Dubcovsky J, Chen C, Yan L. 2005. Molecular characterization of the allelic variation at the VRN-H2 vernalization locus in barley. Mol Breed 15: 395-407.

Dubcovsky J, Loukoianov A, Fu D, Valarik M, Sanchez A, Yan L. 2006. Effect of photoperiod on the regulation of wheat vernalization genes VRN1 and VRN2. Plant Mol Biol 60: 469-480.

Filiz E, Ozdemir BS, Budak F, Vogel JP, Tuna M, Budak H. 2009. Molecular, morphological, and cytological analysis of diverse Brachypodium distachyon inbred lines. Genome 52: 876-890.

Finnegan EJ, Dennis ES. 2007. Vernalization-induced trimethylation of histone $\mathrm{H} 3$ lysine 27 at FLC is not maintained in mitotically quiescent cells. Curr Biol 17: 1978-1983.

Fu D, Szucs P, Yan L, Helguera M, Skinner JS, von Zitzewitz J, Hayes PM, Dubcovsky J. 2005. Large deletions within the first intron in VRN-1 are associated with spring growth habit in barley and wheat. Mol Genet Genomics 273: 54-65.

Fujiwara S, Oda A, Yoshida R, Niinuma K, Miyata K, Tomozoe Y, Tajima T, Nakagawa M, Hayashi K, Coupland G, et al. 2008. Circadian clock proteins LHY and CCA1 regulate SVP protein accumulation to control flowering in Arabidopsis. Plant Cell 20: 2960-2971.

Greb T, Mylne JS, Crevillen P, Geraldo N, An H, Gendall AR, Dean C. 2007. The PHD finger protein VRN5 functions in the epigenetic silencing of Arabidopsis FLC. Curr Biol 17: 73 78.

Greenup A, Peacock WJ, Dennis ES, Trevaskis B. 2009. The molecular biology of seasonal flowering-responses in Arabidopsis and the cereals. Ann Bot 103: 1165-1172.
Griffiths S, Dunford RP, Coupland G, Laurie DA. 2003. The evolution of CONSTANS-like gene families in barley, rice, and Arabidopsis. Plant Physiol 131: 1855-1867.

Helliwell CA, Wood CC, Robertson M, James Peacock W, Dennis ES. 2006. The Arabidopsis FLC protein interacts directly in vivo with SOC1 and FT chromatin and is part of a highmolecular-weight protein complex. Plant J 46: 183-192.

Helliwell CA, Robertson M, Finnegan EJ, Buzas DM, Dennis ES. 2011. Vernalization-repression of Arabidopsis FLC requires promoter sequences but not antisense transcripts. PLoS One 6: e21513.

Hemming MN, Peacock WJ, Dennis ES, Trevaskis B. 2008. Low-temperature and daylength cues are integrated to regulate FLOWERING LOCUS T in barley. Plant Physiol 147: $355-366$.

Heo JB, Sung S. 2011. Vernalization-mediated epigenetic silencing by a long intronic noncoding RNA. Science 331: 76-79.

Hepworth SR, Valverde F, Ravenscroft D, Mouradov A, Coupland G. 2002. Antagonistic regulation of flowering-time gene SOC1 by CONSTANS and FLC via separate promoter motifs. EMBO J 21: 4327-4337.

Higgins JA, Bailey PC, Laurie DA. 2010. Comparative genomics of flowering time pathways using Brachypodium distachyon as a model for the temperate grasses. PLoS One 5: e10065.

Hong SY, Seo PJ, Yang MS, Xiang F, Park CM. 2008. Exploring valid reference genes for gene expression studies in Brachypodium distachyon by real-time PCR. BMC Plant Biol 8: 112 .

Honma T, Goto K. 2001. Complexes of MADS-box proteins are sufficient to convert leaves into floral organs. Nature 409: $525-529$

Huo N, Garvin DF, You FM, McMahon S, Luo MC, Gu YQ, Lazo GR, Vogel JP. 2011. Comparison of a high-density genetic linkage map to genome features in the model grass Brachypodium distachyon. Theor Appl Genet 123: 455-464.

International Barley Genome Sequencing C, Mayer KF, Waugh R, Brown JW, Schulman A, Langridge P, Platzer M, Fincher GB, Muehlbauer GJ, Sato K, et al. 2012. A physical, genetic and functional sequence assembly of the barley genome. $\mathrm{Na}$ ture 491: 711-716.

Jaeger KE, Wigge PA. 2007. FT protein acts as a long-range signal in Arabidopsis. Curr Biol 17: 1050-1054.

Jensen CS, Salchert K, Nielsen KK. 2001. A TERMINAL FLOWER1-like gene from perennial ryegrass involved in floral transition and axillary meristem identity. Plant Physiol 125: $1517-1528$.

Johanson U, West J, Lister C, Michaels S, Amasino R, Dean C. 2000. Molecular analysis of FRIGIDA, a major determinant of natural variation in Arabidopsis flowering time. Science 290: $344-347$.

Karsai I, Szucs P, Meszaros K, Filichkina T, Hayes PM, Skinner JS, Lang L, Bedo Z. 2005. The Vrn-H2 locus is a major determinant of flowering time in a facultative $\mathrm{x}$ winter growth habit barley (Hordeum vulgare L.) mapping population. Theor Appl Genet 110: 1458-1466.

Kim SY, Michaels SD. 2006. SUPPRESSOR OF FRI 4 encodes a nuclear-localized protein that is required for delayed flowering in winter-annual Arabidopsis. Development 133: 4699 4707.

Kim S, Choi K, Park C, Hwang HJ, Lee I. 2006. SUPPRESSOR OF FRIGIDA4, encoding a C2H2-Type zinc finger protein, represses flowering by transcriptional activation of Arabidopsis FLOWERING LOCUS C. Plant Cell 18: 2985-2998.

Kim DH, Doyle MR, Sung S, Amasino RM. 2009. Vernalization: Winter and the timing of flowering in plants. Annu Rev Cell Dev Biol 25: 277-299.

Kobayashi Y, Kaya H, Goto K, Iwabuchi M, Araki T. 1999. A pair of related genes with antagonistic roles in mediating flowering signals. Science 286: 1960-1962.

Koornneef M, Blankestijn-de Vries H, Hanhart C, Soppe W, Peeters T. 1994. The phenotype of some late-flowering mutants is enhanced by a locus on chromosome 5 that is not 
effective in the Landsberg erecta wild-type. Plant $J$ 6: $911-$ 919.

Kumimoto RW, Adam L, Hymus GJ, Repetti PP, Reuber TL, Marion CM, Hempel FD, Ratcliffe OJ. 2008. The Nuclear Factor Y subunits NF-YB2 and NF-YB3 play additive roles in the promotion of flowering by inductive long-day photoperiods in Arabidopsis. Planta 228: 709-723.

Kumimoto RW, Zhang Y, Siefers N, Holt BF III. 2010. NFYC3, NF-YC4 and NF-YC9 are required for CONSTANSmediated, photoperiod-dependent flowering in Arabidopsis thaliana. Plant J 63: 379-391.

Laibach F. 1943. Arabidopsis thaliana (L.) Heyhn. als Object fur Genetische und Entwicklungs-Physiologische Untersuchungen. Botanisches Archiv 44: 439-455.

Lee I, Bleecker A, Amasino R. 1993. Analysis of naturally occurring late flowering in Arabidopsis-thaliana. Mol Gen Genet 237: 171-176.

Lee I, Michaels SD, Masshardt AS, Amasino RM. 1994. The late-flowering phenotype of FRIGIDA and LUMINIDEPENDENS is suppressed in the Landsberg erecta strain of Arabidopsis. Plant J 6: 903-909.

Lee JH, Yoo SJ, Park SH, Hwang I, Lee JS, Ahn JH. 2007. Role of SVP in the control of flowering time by ambient temperature in Arabidopsis. Genes Dev 21: 397-402.

Levy YY, Mesnage S, Mylne JS, Gendall AR, Dean C. 2002. Multiple roles of Arabidopsis VRN1 in vernalization and flowering time control. Science 297: 243-246.

Li C, Dubcovsky J. 2008. Wheat FT protein regulates VRN1 transcription through interactions with FDL2. Plant $J$ 55: 543-554.

Li D, Liu C, Shen L, Wu Y, Chen H, Robertson M, Helliwell CA, Ito T, Meyerowitz E, Yu H. 2008. A repressor complex governs the integration of flowering signals in Arabidopsis. Dev Cell 15: $110-120$.

Li C, Distelfeld A, Comis A, Dubcovsky J. 2011. Wheat flowering repressor VRN2 and promoter $\mathrm{CO} 2$ compete for interactions with NUCLEAR FACTOR-Y complexes. Plant $J$ 67: $763-773$.

Lifschitz E, Eviatar T, Rozman A, Shalit A, Goldshmidt A, Amsellem Z, Alvarez JP, Eshed Y. 2006. The tomato FT ortholog triggers systemic signals that regulate growth and flowering and substitute for diverse environmental stimuli. Proc Natl Acad Sci 103: 6398-6403.

Liljegren SJ, Gustafson-Brown C, Pinyopich A, Ditta GS, Yanofsky MF. 1999. Interactions among APETALA1, LEAFY, and TERMINAL FLOWER1 specify meristem fate. Plant Cell 11: 1007-1018.

Liu C, Xi W, Shen L, Tan C, Yu H. 2009. Regulation of floral patterning by flowering time genes. Dev Cell 16: 711-722.

Liu F, Marquardt S, Lister C, Swiezewski S, Dean C. 2010. Targeted $3^{\prime}$ processing of antisense transcripts triggers Arabidopsis FLC chromatin silencing. Science 327: 94-97.

Livak KJ, Schmittgen TD. 2001. Analysis of relative gene expression data using real-time quantitative PCR and the 2(T)(-Delta Delta C) method. Methods 25: 402-408.

Loukoianov A, Yan L, Blechl A, Sanchez A, Dubcovsky J. 2005. Regulation of VRN-1 vernalization genes in normal and transgenic polyploid wheat. Plant Physiol 138: 2364-2373.

Mathieu J, Warthmann N, Kuttner F, Schmid M. 2007. Export of FT protein from phloem companion cells is sufficient for floral induction in Arabidopsis. Curr Biol 17: 1055-1060.

Michaels SD, Amasino RM. 1999. FLOWERING LOCUS C encodes a novel MADS domain protein that acts as a repressor of flowering. Plant Cell 11: 949-956.

Michaels SD, Bezerra IC, Amasino RM. 2004. FRIGIDA-related genes are required for the winter-annual habit in Arabidopsis. Proc Natl Acad Sci 101: 3281-3285.

Minevich G, Park DS, Blankenberg D, Poole RJ, Hobert O. 2012. CloudMap: A cloud-based pipeline for analysis of mutant genome sequences. Genetics 192: 1249-1269.

Mockler TC, Michael TP, Priest HD, Shen R, Sullivan CM, Givan SA, McEntee C, Kay SA, Chory J. 2007. The DIURNAL project: DIURNAL and circadian expression profiling, model-based pattern matching, and promoter analysis. Cold Spring Harb Symp Quant Biol 72: 353-363.

Mur LA, Allainguillaume J, Catalan P, Hasterok R, Jenkins G, Lesniewska K, Thomas I, Vogel J. 2011. Exploiting the Brachypodium Tool Box in cereal and grass research. New Phytol 191: 334-347.

Mylne JS, Barrett L, Tessadori F, Mesnage S, Johnson L, Bernatavichute YV, Jacobsen SE, Fransz P, Dean C. 2006. LHP1, the Arabidopsis homologue of HETEROCHROMATIN PROTEIN1, is required for epigenetic silencing of FLC. Proc Natl Acad Sci 103: 5012-5017.

Nakagawa M, Shimamoto K, Kyozuka J. 2002. Overexpression of RCN1 and RCN2, rice TERMINAL FLOWER 1/ CENTRORADIALIS homologs, confers delay of phase transition and altered panicle morphology in rice. Plant $J$ 29: $743-750$.

Napp-Zinn K. 1987. Vernalization: environmental and genetic regulation. In Manipulation of Flowering, (ed. Atherton JG), pp. 123-132. Butterworths, London.

Oliver SN, Finnegan EJ, Dennis ES, Peacock WJ, Trevaskis B. 2009. Vernalization-induced flowering in cereals is associated with changes in histone methylation at the VERNALIZATION1 gene. Proc Natl Acad Sci 106: 8386-8391.

Opanowicz M, Vain P, Draper J, Parker D, Doonan JH. 2008. Brachypodium distachyon: Making hay with a wild grass. Trends Plant Sci 13: 172-177.

Pin PA, Benlloch R, Bonnet D, Wremerth-Weich E, Kraft T, Gielen JJ, Nilsson O. 2010. An antagonistic pair of FT homologs mediates the control of flowering time in sugar beet. Science 330: 1397-1400.

Pin PA, Zhang W, Vogt SH, Dally N, Buttner B, Schulze-Buxloh G, Jelly NS, Chia TY, Mutasa-Gottgens ES, Dohm JC, et al. 2012. The role of a pseudo-response regulator gene in life cycle adaptation and domestication of beet. Curr Biol 22: 1095-1101.

Pnueli L, Carmel-Goren L, Hareven D, Gutfinger T, Alvarez J, Ganal M, Zamir D, Lifschitz E. 1998. The SELF-PRUNING gene of tomato regulates vegetative to reproductive switching of sympodial meristems and is the ortholog of CEN and TFL1. Development 125: 1979-1989.

Preston JC, Kellogg EA. 2008. Discrete developmental roles for temperate cereal grass VERNALIZATION1/FRUITFULLlike genes in flowering competency and the transition to flowering. Plant Physiol 146: 265-276.

Ratcliffe OJ, Nadzan GC, Reuber TL, Riechmann JL. 2001. Regulation of flowering in Arabidopsis by an FLC homologue. Plant Physiol 126: 122-132.

Ratcliffe OJ, Kumimoto RW, Wong BJ, Riechmann JL. 2003. Analysis of the Arabidopsis MADS AFFECTING FLOWERING gene family: MAF2 prevents vernalization by short periods of cold. Plant Cell 15: 1159-1169.

Sasani S, Hemming MN, Oliver SN, Greenup A, TavakkolAfshari R, Mahfoozi S, Poustini K, Sharifi HR, Dennis ES, Peacock WJ, et al. 2009. The influence of vernalization and daylength on expression of flowering-time genes in the shoot apex and leaves of barley (Hordeum vulgare). J Exp Bot 60: 2169-2178.

Scarcelli N, Kover PX. 2009. Standing genetic variation in FRIGIDA mediates experimental evolution of flowering time in Arabidopsis. Mol Ecol 18: 2039-2049.

Schlappi MR. 2006. FRIGIDA LIKE 2 is a functional allele in Landsberg erecta and compensates for a nonsense allele of FRIGIDA LIKE 1. Plant Physiol 142: 1728-1738.

Schmitz RJ, Hong L, Michaels S, Amasino RM. 2005. FRIGIDA-ESSENTIAL 1 interacts genetically with FRIGIDA and FRIGIDA-LIKE 1 to promote the winter-annual habit of Arabidopsis thaliana. Development 132: 5471-5478.

Schmitz RJ, Sung S, Amasino RM. 2008. Histone arginine methylation is required for vernalization-induced epigenetic silencing of FLC in winter-annual Arabidopsis thaliana. Proc Natl Acad Sci 105: 411-416.

Schneeberger K, Ossowski S, Lanz C, Juul T, Petersen AH, Nielsen KL, Jorgensen JE, Weigel D, Andersen SU. 2009. 
SHOREmap: Simultaneous mapping and mutation identification by deep sequencing. Nat Methods 6: $550-551$.

Schwartz CJ, Doyle MR, Manzaneda AJ, Rey PJ, Mitchell-Olds T, Amasino RM. 2010. Natural variation of flowering time and vernalization responsiveness in Brachypodium distachyon. Bioenerg Res 3: 38-46.

Scortecci KC, Michaels SD, Amasino RM. 2001. Identification of a MADS-box gene, FLOWERING LOCUS M, that represses flowering. Plant $J$ 26: 229-236.

Searle I, He Y, Turck F, Vincent C, Fornara F, Krober S, Amasino RA, Coupland G. 2006. The transcription factor FLC confers a flowering response to vernalization by repressing meristem competence and systemic signaling in Arabidopsis. Genes Dev 20: 898-912.

Sheldon CC, Burn JE, Perez PP, Metzger J, Edwards JA, Peacock WJ, Dennis ES. 1999. The FLF MADS Box Gene. A repressor of flowering in Arabidopsis regulated by vernalization and methylation. Plant Cell 11: 445-458.

Shimada S, Ogawa T, Kitagawa S, Suzuki T, Ikari C, Shitsukawa N, Abe T, Kawahigashi H, Kikuchi R, Handa H, et al. 2009. A genetic network of flowering-time genes in wheat leaves, in which an APETALA1/FRUITFULL-like gene, VRN1, is upstream of FLOWERING LOCUS T. Plant J 58: 668-681.

Sung S, Amasino RM. 2004. Vernalization in Arabidopsis thaliana is mediated by the PHD finger protein VIN3. Nature 427: $159-164$.

Sung S, He Y, Eshoo TW, Tamada Y, Johnson L, Nakahigashi K, Goto K, Jacobsen SE, Amasino RM. 2006a. Epigenetic maintenance of the vernalized state in Arabidopsis thaliana requires LIKE HETEROCHROMATIN PROTEIN 1. Nat Genet 38: 706-710.

Sung S, Schmitz RJ, Amasino RM. 2006b. A PHD finger protein involved in both the vernalization and photoperiod pathways in Arabidopsis. Genes Dev 20: 3244-3248.

Swiezewski S, Liu F, Magusin A, Dean C. 2009. Cold-induced silencing by long antisense transcripts of an Arabidopsis Polycomb target. Nature 462: 799-802.

Tamaki S, Matsuo S, Wong HL, Yokoi S, Shimamoto K. 2007. $\mathrm{Hd} 3$ a protein is a mobile flowering signal in rice. Science 316: $1033-1036$.

Trevaskis B, Bagnall DJ, Ellis MH, Peacock WJ, Dennis ES 2003. MADS box genes control vernalization-induced flowering in cereals. Proc Natl Acad Sci 100: 13099-13104.

Trevaskis B, Hemming MN, Peacock WJ, Dennis ES. 2006. HvVRN2 responds to daylength, whereas HvVRN1 is regulated by vernalization and developmental status. Plant Physiol 140: $1397-1405$.

Turner A, Beales J, Faure S, Dunford RP, Laurie DA. 2005. The pseudo-response regulator Ppd-H1 provides adaptation to photoperiod in barley. Science 310: 1031-1034.
Vogel J, TIBI. 2010. Genome sequencing and analysis of the model grass Brachypodium distachyon. Nature 463: $763-$ 768.

Vogel JP, Garvin DF, Leong OM, Hayden DM. 2006. Agrobacterium-mediated transformation and inbred line development in the model grass Brachypodium distachyon. Plant Cell Tiss Org 84: 199-211.

Vogel JP, Tuna M, Budak H, Huo N, Gu YQ, Steinwand MA. 2009. Development of SSR markers and analysis of diversity in Turkish populations of Brachypodium distachyon. BMC Plant Biol 9: 88 .

von Zitzewitz J, Szucs P, Dubcovsky J, Yan L, Francia E, Pecchioni N, Casas A, Chen TH, Hayes PM, Skinner JS. 2005. Molecular and structural characterization of barley vernalization genes. Plant Mol Biol 59: 449-467.

Wood CC, Robertson M, Tanner G, Peacock WJ, Dennis ES, Helliwell CA. 2006. The Arabidopsis thaliana vernalization response requires a polycomb-like protein complex that also includes VERNALIZATION INSENSITIVE 3. Proc Nat Acad Sci 103: $14631-14636$.

Woods DP, Hope CL, Malcomber ST. 2011. Phylogenomic analyses of the BARREN STALK1/LAX PANICLE1 (BA1/ LAX1) genes and evidence for their roles during axillary meristem development. Mol Biol Evol 28: 2147-2159.

Xue W, Xing Y, Weng X, Zhao Y, Tang W, Wang L, Zhou H, Yu $\mathrm{S}, \mathrm{Xu} \mathrm{C}, \mathrm{Li} \mathrm{X}$, et al. 2008. Natural variation in Ghd7 is an important regulator of heading date and yield potential in rice. Nat Genet 40: 761-767.

Yan L, Loukoianov A, Tranquilli G, Helguera M, Fahima T, Dubcovsky J. 2003. Positional cloning of the wheat vernalization gene VRN1. Proc Natl Acad Sci 100: 6263-6268.

Yan L, Helguera M, Kato K, Fukuyama S, Sherman J, Dubcovsky J. 2004a. Allelic variation at the VRN-1 promoter region in polyploid wheat. Theor Appl Genet 109: 16771686.

Yan L, Loukoianov A, Blechl A, Tranquilli G, Ramakrishna W, SanMiguel P, Bennetzen JL, Echenique V, Dubcovsky J. 2004b. The wheat VRN2 gene is a flowering repressor down-regulated by vernalization. Science 303: $1640-$ 1644.

Yan L, Fu D, Li C, Blechl A, Tranquilli G, Bonafede M, Sanchez A, Valarik M, Yasuda S, Dubcovsky J. 2006. The wheat and barley vernalization gene VRN3 is an orthologue of FT. Proc Natl Acad Sci 103: 19581-19586.

Yang L, Liu T, Li B, Sui Y, Chen J, Shi J, Wing RA, Chen M. 2012. Comparative sequence analysis of the Ghd7 orthologous regions revealed movement of Ghd7 in the grass genomes. PLoS One 7: e50236.

Zadoks JC, Chang TT, Konzak CF. 1974. Decimal code for growth stages of cereals. Weed Res 14: 415-421. 


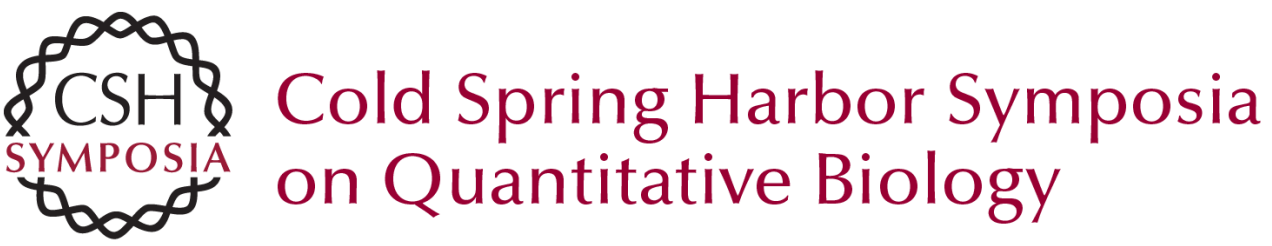

\section{The Molecular Basis of Vernalization in Different Plant Groups}

T.S. Ream, D.P. Woods and R.M. Amasino

Cold Spring Harb Symp Quant Biol 2012 77: 105-115 originally published online April 25, 2013 Access the most recent version at doi:10.1101/sqb.2013.77.014449

References This article cites 120 articles, 51 of which can be accessed free at: http://symposium.cshlp.org/content/77/105.full.html\#ref-list-1

License

Email Alerting Receive free email alerts when new articles cite this article - sign up in Service the box at the top right corner of the article or click here. 